DOI: 10.20472/IAC.2018.043.025

\title{
ANTOINETTE LOMBARD
}

Vaal University of Technology, South Africa

\section{E-LITERACY MASSIFICATION CHALLENGES FOR RURAL AND DISADVANTAGED COMMUNITIES IN SOUTH AFRICA}

\begin{abstract}
:
The massification of e-literacy is a priority of the South African Government as set out in its National Development Plan (NDP) and the National e-Skills Plan (NeSPA) of 2012. Access to broadband and the internet has been identified as a critical challenge in delivering e-literacy programmes to the community-rural and/or disadvantaged-living in remote areas of inter alia the Northern Cape Province of South Africa. E-literacy (or digital literacy) is encapsulated as the basic knowledge of technology all citizens should have to participate in the knowledge economy. In 2017, a survey was conducted to gather basic data regarding the use of technology and the availability of technological resources in the respondents' environment. Each learner who enrolled for an e-literacy programme offered in the Northern Cape and Southern Gauteng region had to complete a registration form that was viewed as a questionnaire for analysis. The purpose of this paper is to identify gaps and provide recommendations from the findings of the survey to address the broadband and internet access challenge in remote areas of Northern Cape so that e-literacy programmes can be rolled out efficiently to the rural and/or disadvantaged community living there in order to deal with poverty, inequality and unemployment and contribute to having an e-literate society by 2030 . A mixed-method survey was adopted in the form of a questionnaire. All learners living in the Northern Cape and Southern Gauteng who registered for an e-literacy course formed part of the non-random, purposive, convenient sample. An inductive approach was used to collect and analyse the data so that findings and conclusions could be drawn. Some of the findings include: i) More than $90 \%$ of the community in the Northern Cape do not have access to broadband and the internet, while the largest part of Southern Gauteng does have connectivity; ii) Rural and/or disadvantaged communities in the Northern Cape have less interest in (or little knowledge of) social media applications such as Facebook and Twitter due to limited access to broadband and the internet; iii) While self-paced learning is feasible in the Southern Gauteng region where access to broadband and the internet is not a problem, this is not yet a reality for the Northern Cape communities; iv) The online e-skills learning path for the communities in the Northern Cape poses a challenge due to little or no access to broadband and the internet.
\end{abstract}

\section{Keywords:}

E-skills, e-literacy, rural, disadvantaged community, internet access, broadband

JEL Classification: 124, 128, 038 